\title{
ANÁLISE COMPARATIVA ENTRE DOIS LOCALIZADORES APICAIS ELETRÔNICOS
}

Alessandra Timponi CRUZ, Adriane PITOME, Maria Isabel Anastacio FARIA, Egas Moniz DE ARAGÃO, Alexandre Roberto HECK

Avaliou-se, in vitro, os localizadores eletrônicos Novapex e Root ZX posicionando instrumentos na posição zero, ou passando com o instrumento além do zero, e voltando nesta posição. As medidas reais de 20 molares inferiores extraídos de humanos foram determinadas posicionando-se os instrumentos até o forame auxiliados pelo microscópio clínico com 20x de aumento. As medidas foram realizadas com um paquímetro. Os dentes foram montados em uma plataforma de polietileno posicionada dentro de uma cuba plástica contendo gelatina preparada com soro fisiológico. Para a análise dos resultados foi usada a diferença das duas medidas (real do dente e obtida pelo aparelho). Os dados das raízes distais e mesiais foram submetidos à análise estatística; na raíz distal o teste Anova mostrou diferença significante entre os grupos $(p<0,01)$ e o teste de Tukey demonstrou diferença entre os valores do Root ZX passando e do Novapex na posição zero. Na raíz mesial o teste Anova não mostrou diferença significante entre os grupos $(p>0,01)$. Concluiu-se que passar com a lima e retornar ao zero para o aparelho Novapex faz este dar valores além do comprimento real do dente, porém quando este é usado no zero apresentou medidas mais próximas às do dente nas duas raízes.

Palavras-chave: Endodontia, Odontometria, Instrumentação 